\title{
Sustained inflation and incremental mean airway pressure trial during conventional and high-frequency oscillatory ventilation in a large porcine model of acute respiratory distress syndrome Ralf M Muellenbach*, Markus Kredel, Bernd Zollhoefer, Christian Wunder, Norbert Roewer and Joerg Brederlau
}

\author{
Address: Department of Anaesthesiology, University of Wuerzburg Oberduerrbacher Strasse 6, 97080 Wuerzburg, Germany \\ Email: Ralf M Muellenbach* - muellenbac_r@klinik.uni-wuerzburg.de; Markus Kredel - kredel_m@klinik.uni-wuerzburg.de; \\ Bernd Zollhoefer - bernd@zollhoefers.de; Christian Wunder - christian.wunder@mail.uni-wuerzburg.de; \\ Norbert Roewer - roewer_n@klinik.uni-wuerzburg.de; Joerg Brederlau - brederlau_j@klinik.uni-wuerzburg.de \\ * Corresponding author
}

Published: 22 June 2006

BMC Anesthesiology 2006, 6:8 doi:10.1 186/147/-2253-6-8

This article is available from: http://www.biomedcentral.com/I47I-2253/6/8

(C) 2006 Muellenbach et al; licensee BioMed Central Ltd.

This is an Open Access article distributed under the terms of the Creative Commons Attribution License (http://creativecommons.org/licenses/by/2.0), which permits unrestricted use, distribution, and reproduction in any medium, provided the original work is properly cited.

\begin{abstract}
Background: To compare the effect of a sustained inflation followed by an incremental mean airway pressure trial during conventional and high-frequency oscillatory ventilation on oxygenation and hemodynamics in a large porcine model of early acute respiratory distress syndrome.

Methods: Severe lung injury (Ali) was induced in 18 healthy pigs $(55.3 \pm 3.9 \mathrm{~kg}$, mean $\pm \mathrm{SD}$ ) by repeated saline lung lavage until $\mathrm{PaO}_{2}$ decreased to less than $60 \mathrm{mmHg}$. After a stabilisation period of 60 minutes, the animals were randomly assigned to two groups: Group I (Pressure controlled ventilation; $\mathrm{PCV}$ ): $\mathrm{FIO}_{2}=1.0, \mathrm{PEEP}=5 \mathrm{cmH}_{2} \mathrm{O}, \mathrm{V}_{\mathrm{T}}=6 \mathrm{ml} / \mathrm{kg}$, respiratory rate $=30 / \mathrm{min}, \mathrm{I:E}=\mathrm{I}: \mathrm{l}$; group 2 (High-frequency oscillatory ventilation; $\mathrm{HFOV}$ ): $\mathrm{FIO}_{2}=1.0$, Bias flow $=30 \mathrm{l} / \mathrm{min}$, Amplitude $=60 \mathrm{cmH}_{2} \mathrm{O}$, Frequency $=6 \mathrm{~Hz}$, I:E = I:I. A sustained inflation ( $\mathrm{SI} ; 50 \mathrm{cmH}_{2} \mathrm{O}$ for $60 \mathrm{~s}$ ) followed by an incremental mean airway pressure (mPaw) trial (steps of $3 \mathrm{cmH}_{2} \mathrm{O}$ every 15 minutes) were performed in both groups until $\mathrm{PaO}_{2}$ no longer increased. This was regarded as full lung inflation. The $\mathrm{mPaw}$ was decreased by $3 \mathrm{cmH}_{2} \mathrm{O}$ and the animals reached the end of the study protocol. Gas exchange and hemodynamic data were collected at each step.
\end{abstract}

Results: The SI led to a significant improvement of the $\mathrm{PaO}_{2} / \mathrm{FiO}_{2}$-Index (HFOV: $200 \pm 100$ vs. PCV: $58 \pm 15$ and $\mathrm{T}_{\text {Ali: }} 57 \pm 12 ; \mathrm{P}<0.00 \mathrm{I}$ ) and $\mathrm{PaCO}_{2}$-reduction (HFOV: $42 \pm 5$ vs. PCV: $62 \pm 13$ and $\mathrm{T}_{\mathrm{Ali}}: 55 \pm 9 ; \mathrm{p}<0.00 \mathrm{I}$ ) during HFOV compared to lung injury and PCV. Augmentation of mPaw improved gas exchange and pulmonary shunt fraction in both groups, but at a significant lower $\mathrm{mPaw}$ in the HFOV treated animals. Cardiac output was continuously deteriorating during the recruitment manoeuvre in both study groups (HFOV: $\mathrm{T}_{\text {Ali }}: 6.1 \pm \mathrm{I}$ vs. $\mathrm{T}_{75}: 3.4 \pm 0.4 ; \mathrm{PCV}: \mathrm{T}_{\mathrm{Ali}}: 6.7$ \pm 2.4 vs. $\left.T_{75}: 4 \pm 0.5 ; \mathrm{p}<0.00 \mathrm{I}\right)$.

Conclusion: A sustained inflation followed by an incremental mean airway pressure trial in HFOV improved oxygenation at a lower $\mathrm{mPaw}$ than during conventional lung protective ventilation. HFOV but not PCV resulted in normocapnia, suggesting that during HFOV there are alternatives to tidal ventilation to achieve $\mathrm{CO}_{2}$-elimination in an "open lung" approach. 


\section{Background}

Current treatment goals in patients with acute respiratory distress syndrome (ARDS) are to maintain adequate oxygenation while minimizing ventilator-associated lung injury (VILI) [1,2]. Several experimental studies have shown that mechanical ventilation (MV) can cause or perpetuate lung injury if alveolar overdistension, repetitive collapse and reopening of alveolar units occur $[3,4]$. Based on these findings, it is now recommended that patients with ARDS should be ventilated with low tidal volumes to limit end-inspiratory pressure and alveolar overdistension, while maintaining the lung open with sufficient positive end-exspiratory pressure (PEEP) to prevent alveolar collapse $[5,6]$. Although this lung protective strategy significantly reduces mortality in patients with ARDS, it is recognized that low peak pressure ventilation favours further lung derecruitment $[7,8]$. Recruitment manoeuvres (RM) composed of periodic sighs or sustained inflations to reexpand the collapsed lung units have been proposed as an adjunct to MV during general anaesthesia and ARDS [9-11]. Such manoeuvres may lead to immediate improvements in respiratory compliance and oxygenation. However, in clinical practice, many patients with ARDS remain hypoxemic using conventional lung protective ventilatory approaches, and the morbidity and mortality of patients suffering from ARDS remains unacceptably high $[5,6,12]$.

High-frequency oscillatory ventilation (HFOV) is an alternative to conventional lung protective ventilation. The application of tidal volumes less than $6 \mathrm{ml} / \mathrm{kg}$ body weight combined with a high mean airway pressure (mPaw) to avoid lung overdistension and derecruitment, provides a basis for an alternative lung protective ventilatory strategy $[13,14]$. In a multicenter randomized controlled trial, Derdak and colleagues showed a significant early improvement of the $\mathrm{PaO}_{2} / \mathrm{FiO}_{2}$-Ratio in the HFOV group, while applying a significantly higher mPaw [15]. In small animal studies of acute lung injury and neonatal and paediatric respiratory distress syndrome, HFOV, utilizing an aggressive lung recruiting strategy, was shown to be safe and improved oxygenation compared to conventional mechanical ventilation [16-18]. HFOV, as a rescue therapy, is increasingly employed in intensive care patients with severe ARDS who remain hypoxemic during conventional ventilation.

The aim of this study was to evaluate the immediate effect of a sustained inflation ( $\left.\mathrm{SI}=50 \mathrm{cmH}_{2} \mathrm{O}\right)$ followed by an incremental and matched mean positive airway pressure augmentation in a large porcine model of severe ARDS with two different lung protective ventilation strategies (low-tidal pressure controlled ventilation versus HFOV) on gas exchange and hemodynamics. We hypothesized, that HFOV will reverse hypoxia at a lower mPaw than con- ventional lung protective ventilation, thereby aiming for a more lung protective recruitment strategy.

\section{Methods}

The study was approved by the Laboratory Animal Care and Use Committee of the District of Unterfranken, Germany and conducted in compliance with the National Institutes of Health guidelines for ethical animal research.

\section{Animal preparation}

Eighteen healthy female pigs (weight $55.3 \pm 3.9 \mathrm{~kg}$, mean \pm SD), Pietrain breed, were fasted for 24 hours with free water access. After intramuscular premedication with ketamin $(10 \mathrm{mg} / \mathrm{kg})$, xylazine hydrochloride $(1 \mathrm{mg} / \mathrm{kg})$ and atropine $(25 \mu \mathrm{g} / \mathrm{kg})$ an intravenous line was obtained, and anaesthesia was induced with $10 \mathrm{mg} / \mathrm{kg}$ thiopental. All animals were positioned supine and orally intubated with a cuffed 8.5-mm ID endotracheal tube with an additional side lumen (Rueschelit ${ }^{\circledR}$, Ruesch, Kernen, Germany). Anaesthesia and muscle relaxation were maintained with continuous infusion of $5-10 \mathrm{mg} / \mathrm{kg} / \mathrm{h}$ thiopental, $0.01 \mathrm{mg} / \mathrm{kg} / \mathrm{h}$ fentanyl and $0.1 \mathrm{mg} / \mathrm{kg} / \mathrm{h}$ pancuronium throughout the experiment. Pressure controlled ventilation (PCV) was adjusted with a PEEP of $5 \mathrm{cmH}_{2} \mathrm{O}$, a tidal volume of $6 \mathrm{ml} / \mathrm{kg}$, a respiratory rate (RR) of 30/ min and an inspiratory to exspiratory ratio (I:E) of $1: 1$. The inspiratory oxygen fraction $\left(\mathrm{FIO}_{2}\right)$ was kept at 1.0. Continuous electrocardiography (Servomed ${ }^{\circledast}$, Hellige, Freiburg i. Br., Germany), pulsoxymetry, capnography and distal tracheal pressure monitoring were performed. A 20-gauge arterial catheter (Vygon, Ecouen, France) and a 9.0-French introducer sheath (Arrow, Reading, PA, USA) were inserted in the left carotid artery and in the right internal jugular vein respectively by using real-time ultrasound guidance (SonoSite 180 Plus $^{\circledast}$, SonoSite Inc., Botell, WA, USA). A 7.5-French flow-directed pulmonary artery catheter (831F75, Edwards Lifescience, Irvine, CA, USA) was inserted under transduced pressure guidance. The core temperature, as determined by the pulmonary artery catheter, was maintained at $38.0^{\circ} \pm 0.5^{\circ} \mathrm{C}$ during the experiment by using a heating pad. After a bolus of $500 \mathrm{ml}$ colloid solution (Voluven 6\% HES 130/0.4, Fresenius Kabi, Bad Homburg, Germany) prior the recruitment manoeuvre a continuous infusion of $4-5 \mathrm{ml} / \mathrm{kg} / \mathrm{h}$ balanced electrolyte solution was administered for adequate hydration.

\section{Data acquisition}

All hemodynamic data were taken in the supine position referenced to atmospheric pressure at the mid-chest level. Mean arterial pressure (MAP), mean pulmonary artery pressure (MPAP), central venous pressure (CVP) and pulmonary artery occlusion pressure (PCWP) were recorded (Servomed ${ }^{\circledR}$, Hellige, Freiburg i. Br., Germany). Heart rate (HR) was traced by the electrocardiogram. Cardiac output 
(CO) was measured by using standard thermodilution techniques and expressed as the mean of three consecutive measurements (Explorer ${ }^{\circledR}$, Edwards Lifescience, Irvine, CA, USA), each consisting of a $10 \mathrm{ml}$ bolus of icecold saline into the right atrium randomly during the respiratory cycles. Blood samples were drawn from systemic arterial and pulmonary arterial lines and were immediately analyzed for oxygen pressure $\left(\mathrm{PO}_{2}\right)$, carbon dioxide pressure $\left(\mathrm{PCO}_{2}\right)$ and $\mathrm{pH}$ using standard blood gas electrodes (ABL 505 ${ }^{\circledR}$, Radiometer, Bronshoj, Denmark). In each sample, hemoglobin and oxygen saturation $\left(\mathrm{SO}_{2}\right)$ were measured using specific spectroscopy (OSM3 ${ }^{\circledR}$, Radiometer, Copenhagen, Denmark). Arterial $\left(\mathrm{CaO}_{2}\right)$, mixed venous $\left(\mathrm{CvO}_{2}\right)$ and pulmonary capillary $\left(\mathrm{CCO}_{2}\right)$ oxygen contents $(\mathrm{ml} / \mathrm{dl})$ were calculated using the standard formula: Oxygen content $=$ hemoglobin concentration $\times$ $1.34 \times\left(\% \mathrm{O}_{2}\right.$ saturation/100) $+\mathrm{PO}_{2} \times 0.0031$. Oxygen delivery $\left(\mathrm{DO}_{2}\right)$ and consumption $\left(\mathrm{VO}_{2}\right)$ were determined using the conventional formulas $\mathrm{DO}_{2}=\mathrm{CO} \times \mathrm{CaO}_{2} \times 10$ and $\mathrm{VO}_{2}=\mathrm{CO} \times\left(\mathrm{CaO}_{2}-\mathrm{CvO}_{2}\right) \times 10$. The standard shunt equation was used to calculate the amount of venous admixture (Qs/Qt): $\left(\mathrm{CCO}_{2}-\mathrm{CaO}_{2}\right) /\left(\mathrm{CCO}_{2}-\mathrm{CvO}_{2}\right)$. Mean airway pressure was measured at the side lumen ending at the tubes tip using an air filled pressure transducer (PM8050 ${ }^{\circledR}$, Draeger, Luebeck, Germany) referenced to atmospheric pressure. The oxygenation index was calculated using the following formula: $\mathrm{OI}=(\mathrm{FiO} 2 \times \mathrm{mPaw} \times$ 100) $/ \mathrm{PaO}_{2}$ [19].

\section{Experimental protocol}

After instrumentation the animals were stabilized for 30 min in the supine position and baseline measurements $\left(\mathrm{T}_{\text {baseline }}\right)$ were performed. Severe lung injury was induced by bilateral pulmonary lavages with $30 \mathrm{ml} / \mathrm{kg}$ isotonic saline $\left(38^{\circ} \mathrm{C}\right)$, repeated every 10 minutes until $\mathrm{PaO}_{2}$ decreased to less than $60 \mathrm{mmHg}$ and remained stable for 60 minutes with unchanged ventilatory parameters.

\section{Recruitment manoeuvres and ventilator adjustment}

After stabilisation post injury measurements $\left(\mathrm{T}_{\mathrm{ali}}\right)$ were obtained and the animals were randomly assigned to the following treatment groups $(n=9 /$ group $)$ :

1. PCV: $\mathrm{FIO}_{2}=1.0, \mathrm{PEEP}=5 \mathrm{cmH}_{2} \mathrm{O}, \mathrm{V}_{\mathrm{T}}=6 \mathrm{ml} / \mathrm{kg}, \mathrm{RR}=$ $30 / \mathrm{min}, \mathrm{I}: \mathrm{E}=1: 1$

2. High-frequency oscillatory ventilation (HFOV): $\mathrm{FIO}_{2}=$ 1.0 , Bias flow $=30 \mathrm{l} / \mathrm{min}$, Amplitude $=60 \mathrm{cmH}_{2} \mathrm{O}$, Frequency $=6 \mathrm{~Hz}, \mathrm{I}: \mathrm{E}=1: 1$ (Sensor Medics $3100 \mathrm{~B}$, Yorba Linda, CA, USA)

A sustained inflation (SI) was applied by an exspiratory hold for $60 \mathrm{~s}$ (PEEP $50 \mathrm{cmH}_{2} \mathrm{O}$ ) in the PCV group and increasing the mean airway pressure (mPaw) to 50 $\mathrm{cmH}_{2} \mathrm{O}$ without oscillation for $60 \mathrm{~s}$ in the HFOV group. In both groups, the mPaw was then adjusted $3 \mathrm{cmH}_{2} \mathrm{O}$ higher than after acute lung injury $\left(\mathrm{T}_{\mathrm{Ali}}\right)$ and increased in steps of $3 \mathrm{cmH}_{2} \mathrm{O}$ until $\mathrm{PaO}_{2}$ no longer increased or began to decline. This was regarded as full lung inflation or the beginning of lung overdistension. Afterwards mPaw was reduced by $3 \mathrm{cmH}_{2} \mathrm{O}$ and the animals reached the end of the study protocol [20]. A 15-min equilibration period between each modification was followed by measurements of hemodynamics, arterial blood gases and respiratory parameters. Intrinsic PEEP was measured during PCV by means of an endexspiratory occlusion manoeuvre ( 5 secs) at each time point and was always less than 1 $\mathrm{cmH}_{2} \mathrm{O}$. Pulmonary artery blood gases were measured at following time points: $\mathrm{T}_{\text {Baseline' }}, \mathrm{T}_{\mathrm{Ali}^{\prime}} \mathrm{T}_{60}$ and $\mathrm{T}_{120}$. At the end of the study the animals were killed using an intravenous overdose of sodium thiopental and T6 $1^{\circledR}$ (Intervet, Unterschleissheim, Germany). The study protocol and time course of the whole experiment is outlined in Fig. 1.

\section{Statistical analysis}

The data were tested for normal distribution using the Kolmogorov-Smirnov test. Values are reported as mean \pm SD. The data were analyzed using SigmaStat for Windows, version 2.03 (Systat Software Inc., Point Richmond, USA). Two-way analysis of variance (ANOVA) for repeated measurements was used for data analysis. Student-Newman-Keuls post hoc test was used for comparison of significant ANOVA results within and between the groups. $\mathrm{P}$ values of less than 0.05 were considered significant. Because of different numbers of animals during the time points $T_{90}$ to $T_{150}$ no data were statistically analyzed.

\section{Results}

Detailed data regarding hemodynamics, gas exchange and respiratory parameters are presented in tables 1 and 2 . $\mathrm{PaO}_{2}{ }^{-}, \mathrm{OI}-, \mathrm{PaCO}_{2}$ and $\mathrm{CO}$-changes during the experimental period are displayed in figures 2, 3, 4, 5 .

\section{Lung injury}

All animals survived the complete study period. Acute lung injury was induced in all animals by means of repeated saline lung lavages $(18 \pm 3)$ with significant changes $(\mathrm{p} \leq 0.05)$ in $\mathrm{pHa}, \mathrm{PaCO}_{2}, \mathrm{OI}, \mathrm{PaO}_{2} / \mathrm{FiO}_{2}$-Index, $\mathrm{VO}_{2}, \mathrm{SvO}_{2}, \mathrm{mPaw}, \mathrm{PIP}, \mathrm{MAP}, \mathrm{CVP}, \mathrm{MPAP}, \mathrm{Qs} / \mathrm{Qt}$ - ratio and CO: pHa decreased from $7.46 \pm 0.08$ to $7.35 \pm 0.06$, $\mathrm{PaCO}_{2}$ increased from $39.8 \pm 5.9$ to $54.9 \pm 11.8 \mathrm{mmHg}$, OI increased from $1.7 \pm 0.2$ to $27.6 \pm 8.5, \mathrm{PaO}_{2} / \mathrm{FiO}_{2}$ Index declined from $564 \pm 41.9$ to $57 \pm 12.2 \mathrm{mmHg}, \mathrm{VO}_{2}$ increased from $174 \pm 40.0$ to $212 \pm 61.5 \mathrm{ml} / \mathrm{min} . / \mathrm{m}^{2}$, $\mathrm{SvO}_{2}$ decreased from $83 \pm 5.0$ to $61 \pm 11.0 \%$, mPaw increased from $9.5 \pm 0.5$ to $14.9 \pm 1.3 \mathrm{cmH}_{2} \mathrm{O}$, PIP increased from $14.1 \pm 1.2$ to $24.8 \pm 2.6 \mathrm{cmH}_{2} \mathrm{O}, \mathrm{MAP}$ increased from $73 \pm 11$ to $93 \pm 10 \mathrm{mmHg}$, CVP increased from $5 \pm 2.3$ to $7 \pm 2.4 \mathrm{mmHg}$, MPAP increased from 18 \pm 3.8 to $36 \pm 5.5 \mathrm{mmHg}$, Qs/Qt increased from $8 \pm 4$ to 53 


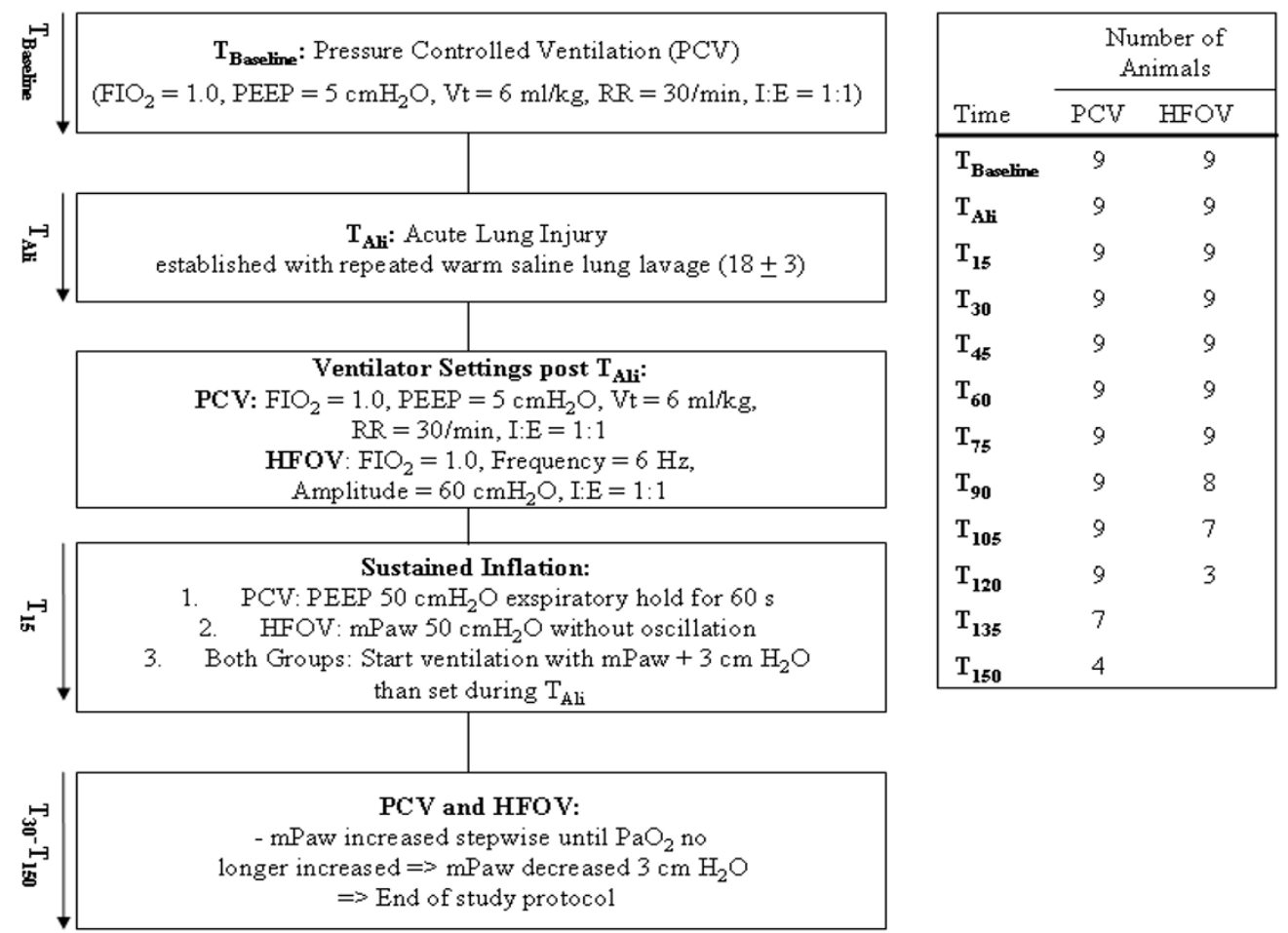

\section{Figure I}

Study protocol and time course. $\mathrm{FiO}_{2}=$ fraction of inspired oxygen; $\mathrm{PEEP}=$ positive endexspiratory pressure; $\mathrm{Vt}=$ tidal volume; $\mathrm{RR}=$ respiratory rate; $\mathrm{I}: \mathrm{E}=$ inspiratory:exspiratory-ratio; $\mathrm{PCV}=$ pressure controlled ventilation; $\mathrm{HFOV}=\mathrm{High}-\mathrm{fre}-$ quency oscillatory ventilation; $\mathrm{mPaw}=$ mean pulmonary airway pressure; $\mathrm{PaO}_{2}=$ arterial oxygen pressure

$\pm 8 \%$, CO increased from $4.6 \pm 1.4$ to $6.4 \pm 1.8 \mathrm{l} / \mathrm{min}$. No significant differences could be detected between the 2 groups for the parameters tested at time points $\mathrm{T}_{\text {Baseline }}$ and $\mathrm{T}_{\text {Ali }}$ (tables 1 and 2, fig. 2, 3, 4 and 5).

\section{Pulmonary gas exchange}

The SI and rising mPaw led to a significant improvement of $\mathrm{OI}$ and $\mathrm{PaO}_{2} / \mathrm{FiO}_{2}$-ratio in the HFOV group compared to $\mathrm{T}_{\mathrm{Ali}}$ and the PCV group from $\mathrm{T}_{15}$ to $\mathrm{T}_{75}\left(\mathrm{p} \leq 0.001 \mathrm{vs}\right.$. $\mathrm{T}_{\mathrm{Al}}$ ${ }_{\mathrm{i}}$ and PCV; fig. 2 and 3). However, in the PCV group the SI was associated with a deterioration of $\mathrm{OI}$ and $\mathrm{PaO}_{2} / \mathrm{FiO}_{2}-$ Ratio at $\mathrm{T}_{15}$. With rising mPaw oxygenation in the PCV group increased and was significantly improved at $\mathrm{T}_{60}$ and $\mathrm{T}_{75}$ ( $\mathrm{p} \leq 0.001$ vs. $\mathrm{T}_{\mathrm{Ali}}$; fig. 2 and 3 ). At $\mathrm{T}_{60}$ the $\mathrm{SvO}_{2}$ was significantly improved in both groups when compared to $\mathrm{T}_{\mathrm{Ali}}$ without detectable significant differences between the groups ( $\mathrm{p} \leq 0.05$ vs. $\mathrm{T}_{\mathrm{Ali}}$; table 2 ). $\mathrm{PaCO}_{2}$ improved significantly in the HFOV group compared to $\mathrm{T}_{\mathrm{Ali}}$ and the PCV group ( $\mathrm{p} \leq 0.001$; fig. 4). The PCV animals remained hypercapnic with a $\mathrm{PaCO}_{2}$ greater $55 \mathrm{mmHg}$ resulting in a pH of less than 7.35 throughout the experiment (fig. 4).

\section{Hemodynamics and oxygen delivery}

HR and MAP showed a downward drift during the SI and incremental mPaw trial in both groups, but it was not necessary to stop the recruitment manoeuvre due to critical hemodynamic compromise.

HR was significantly lower at $\mathrm{T}_{15}$ in the HFOV vs. the PCV group and from $\mathrm{T}_{15}$ to $\mathrm{T}_{60}$ vs. $\mathrm{T}_{\text {Ali }}$ (table 1 ). MAP significantly decreased at $\mathrm{T}_{60}$ in the HFOV animals and at $\mathrm{T}_{75}$ in both groups compared to $\mathrm{T}_{\text {Ali }}$ (table 1). CVP and PCWP showed a significant elevation in the HFOV group from $\mathrm{T}_{15}$ to $\mathrm{T}_{75}$ compared to $\mathrm{T}_{\mathrm{Ali}}$ and CVP was significantly higher than in the PCV group during the same time course (table 1). MPAP was significantly lower in both groups compared to $\mathrm{T}_{\mathrm{Ali}}$ and at $\mathrm{T}_{15}$ significantly lower in the HFOV than PCV animals (table 1). CO was significantly lower and continuously falling in the HFOV group (fig. 5). At $\mathrm{T}_{15} \mathrm{CO}$ was significantly lower in the HFOV compared to PCV group and from $\mathrm{T}_{45}$ to $\mathrm{T}_{75} \mathrm{CO}$ was significantly decreased compared to $\mathrm{T}_{\mathrm{Ali}}$ in PCV animals (fig. 5). $\mathrm{Qs} / \mathrm{Qt}$ was at $\mathrm{T}_{60}$ significant lower in both groups compared to injury and significant reduced in the HFOV versus PCV group (table 1). 
Table I: Hemodynamic variables during recruitment manoeuvre.

\begin{tabular}{|c|c|c|c|c|c|c|c|}
\hline & Group & $\mathbf{T}_{\text {baseline }}$ & $\mathbf{T}_{\mathrm{ALI}}$ & $\mathbf{T}_{15}$ & $\mathbf{T}_{30}$ & $\mathbf{T}_{45}$ & $\mathbf{T}_{60}$ \\
\hline \multirow{2}{*}{$\begin{array}{l}\text { Number of } \\
\text { animals }\end{array}$} & PCV & 9 & 9 & 9 & 9 & 9 & 9 \\
\hline & HFOV & 9 & 9 & 9 & 9 & 9 & 9 \\
\hline HR & PCV & $71 \pm 18$ & $85 \pm 22$ & $85 \pm 18$ & $76 \pm 20$ & $73 \pm 24$ & $73 \pm 23$ \\
\hline$[/ \mathrm{min}]$ & HFOV & $66 \pm 9$ & $79 \pm 6$ & $67 \pm 5^{*+}$ & $63 \pm 3^{*}$ & $62 \pm 4^{*}$ & $64 \pm 5^{*}$ \\
\hline MAP & PCV & $75 \pm 13^{* * * *}$ & $93 \pm 11$ & $84 \pm 17$ & $86 \pm 11$ & $86 \pm 10$ & $86 \pm 10$ \\
\hline [mmHg] & HFOV & $71 \pm 8 * * *$ & $94 \pm 9$ & $87 \pm 7$ & $87 \pm 5$ & $85 \pm 6$ & $83 \pm 7 * *$ \\
\hline CVP & PCV & $4.9 \pm 2.4^{* * * *}$ & $7.1 \pm 2.3$ & $7.6 \pm 1.8$ & $8.1 \pm 1.8$ & $8.6 \pm 2.1^{* *}$ & $9.4 \pm 2.5^{* * * *}$ \\
\hline$[\mathrm{mmHg}]$ & HFOV & $5.2 \pm 2.2^{* *}$ & $6.4 \pm 2.5$ & $9.7 \pm 2.0 * * *+$ & $10.4 \pm 2.1 * * *+$ & $10.7 \pm 1.9 * * *+$ & $11.9 \pm 2.0 * * *+$ \\
\hline MPAP & PCV & $19 \pm 5 * * *$ & $37 \pm 6$ & $34 \pm 5^{* * *}$ & $31 \pm 4 * * *$ & $28 \pm 4 * * *$ & $30 \pm 3^{* * *}$ \\
\hline [mmHg] & HFOV & $17 \pm 2^{* * * *}$ & $34 \pm 5$ & $30 \pm 6^{* *+}$ & $27 \pm 4^{* * *}$ & $29 \pm 4 * * *$ & $31 \pm 4 * *$ \\
\hline PCWP & PCV & $7.3 \pm 2.9$ & $8.7 \pm 2.1$ & $10.2 \pm 2.0$ & $10.0 \pm 2.3$ & $12.0 \pm 3.0 * * *$ & $12.6 \pm 3.0 * * *$ \\
\hline [mmHg] & HFOV & $7.4 \pm 1.6 * *$ & $9.7 \pm 3.7$ & $12.2 \pm 2.8^{* *}$ & $13.0 \pm 2.9 * * *+$ & $12.8 \pm 1.8^{* * * *}$ & $14.0 \pm 1.9 * * *$ \\
\hline Qs/Qt & PCV & $0.09 \pm 0.05^{* * *}$ & $0.54 \pm 0.10$ & & & & $0.31 \pm 0.17^{* *}$ \\
\hline \multirow[t]{2}{*}{ (ratio) } & HFOV & $0.06 \pm 0.01 * * *$ & $0.52 \pm 0.07$ & & & & $0.10 \pm 0.04^{* * * *+}$ \\
\hline & Group & $\mathbf{T}_{75}$ & $\mathbf{T}_{90}$ & $\mathbf{T}_{105}$ & $\mathbf{T}_{120}$ & $\mathbf{T}_{135}$ & $\mathbf{T}_{150}$ \\
\hline \multirow{2}{*}{$\begin{array}{l}\text { Number of } \\
\text { animals }\end{array}$} & $\mathrm{PCV}$ & 9 & 9 & 9 & 9 & 7 & 4 \\
\hline & HFOV & 9 & 8 & 7 & 3 & & \\
\hline HR & PCV & $71 \pm 18$ & $74 \pm 18$ & $80 \pm 18$ & $83 \pm 19$ & $92 \pm 18$ & $100 \pm 16$ \\
\hline$[/ \mathrm{min}]$ & HFOV & $67 \pm 8$ & $77 \pm 10$ & $82 \pm 13$ & $97 \pm 13$ & & \\
\hline MAP & PCV & $83 \pm 7^{*}$ & $79 \pm 6$ & $76 \pm 10$ & $75 \pm 8$ & $73 \pm 9$ & $77 \pm 4$ \\
\hline$[\mathrm{mmHg}]$ & HFOV & $78 \pm 6 * * *$ & $77 \pm 8$ & $80 \pm 6$ & $80 \pm 5$ & & \\
\hline CVP & PCV & $10.4 \pm 2.4^{* * *}$ & $\mid I .1 \pm 2.0$ & $11.7 \pm 2.1$ & $12.7 \pm 3.0$ & $13.4 \pm 2.3$ & $14.5 \pm 2.5$ \\
\hline$[\mathrm{mmHg}]$ & HFOV & $12.8 \pm 2.0^{* * * *+}$ & $13.1 \pm 1.8$ & $13.4 \pm 2.6$ & $14.7 \pm 2.9$ & & \\
\hline MPAP & $\mathrm{PCV}$ & $32 \pm 3^{* * *}$ & $33 \pm 3$ & $35 \pm 4$ & $37 \pm 3$ & $39 \pm 5$ & $41 \pm 2$ \\
\hline [mmHg] & HFOV & $32 \pm 4^{*}$ & $35 \pm 5$ & $36 \pm 4$ & $37 \pm 4$ & & \\
\hline PCWP & PCV & $13.4 \pm 2.1$ **** & $13.6 \pm 2.8$ & $15.4 \pm 3.1$ & $17.3 \pm 3.5$ & $19.0 \pm 2.7$ & $19.3 \pm 1.9$ \\
\hline [mmHg] & HFOV & $15.9 \pm 2.4^{* * *+}$ & $16.4 \pm 2.5$ & $16.3 \pm 3.3$ & $18.0 \pm 2.6$ & & \\
\hline Qs/Qt & PCV & & & & $0.06 \pm 0.02$ & & \\
\hline (ratio) & HFOV & & & & $0.04 \pm 0.02$ & & \\
\hline
\end{tabular}

Data are mean \pm standard deviation; Two-way-ANOVA with repeated measurements (Student-Newman-Keuls post hoc test): $* \mathrm{P}<0.05$ vs. $\mathrm{T}_{\mathrm{Ali}}{ }^{* * *}$ $\mathrm{P}<0.01$ vs. $\mathrm{T}_{\mathrm{Ali}}$; $* * * \mathrm{p}<0.00 \mathrm{I}$ vs. $\mathrm{T}_{\mathrm{Ali}}$; HFOV compared with $\mathrm{PCV}:+\mathrm{p}<0.0 \mathrm{I}$. $\mathrm{PCV}=$ pressure controlled ventilation; HFOV $=$ High-frequency oscillatory ventilation; $H R=$ heart rate; $M A P=$ mean arterial pressure; $C V P=$ central venous pressure; $M P A P=$ mean pulmonary artery pressure; $\mathrm{PCWP}=$ pulmonary capillary wedge pressure; $\mathrm{Qs} / \mathrm{Qt}=$ pulmonary shunt fraction.

\section{Discussion}

This study investigated the impact of a sustained inflation followed by an incremental and matched mean airway pressure trial during HFOV and conventional lung protective ventilation on gas exchange and hemodynamics. The major findings of our study are: 1) Combination of HFOV and SI with rising mPaw improved oxygenation and resulted in a significant reduction of pulmonary shunt fraction at a lower mPaw than during conventional lung protective ventilation. 2) The SI and rising mPaw resulted in normocapnia in the HFOV but not in the PCV group 3) Both groups exhibited a continuously deterioration in cardiac output with rising mPaw.

The treatment of severe hypoxemia in ARDS is highly dependent on the recruitment and maintenance of lung volume [21,22]. This is related to the dynamic reopening of previously collapsed lung units by increasing transpulmonary pressure. In order to assess gas exchange at com- parable levels, we chose to perform a SI followed by stepwise increases in mPaw, which was measured continuously in the trachea using a pressure transducer fast enough to detect pressure changes at 6 Hertz. In both groups we used the same SI of $50 \mathrm{cmH}_{2} \mathrm{O}$ for 60 seconds and afterwards set the mPaw $3 \mathrm{cmH}_{2} \mathrm{O}$ higher than after lung injury. The $\mathrm{PaO}_{2} / \mathrm{FiO}_{2}$-Ratio increased and the $\mathrm{OI}$ decreased significantly in the HFOV, but not in the PCV group (fig. 2 and 3). Our findings are similar to those of previous studies, showing that HFOV therapy is safe and results in early improvements in oxygenation compared to conventional ventilation. Since very small tidal volumes are generated with HFOV, there is little tidal recruitment of the injured lung, recruitment of lung volume appears to be essential in this setting $[18,23]$. The improvement in oxygenation seems to correspond with increases in lung volume [24]. In the HFOV animals this increase was presumably maintained after the SI resulting in significant $\mathrm{PaO}_{2} / \mathrm{FiO}_{2}$ enhancement. The favourable 
Table 2: Variables of Gas exchange during recruitment manoeuvre.

\begin{tabular}{|c|c|c|c|c|c|c|c|}
\hline & Group & $\mathbf{T}_{\text {baseline }}$ & $\mathbf{T}_{\mathrm{ALI}}$ & $\mathbf{T}_{15}$ & $\mathbf{T}_{30}$ & $\mathbf{T}_{45}$ & $\mathbf{T}_{60}$ \\
\hline \multirow{4}{*}{$\begin{array}{l}\text { Number of } \\
\text { animals } \\
\text { pHa }\end{array}$} & PCV & 9 & 9 & 9 & 9 & 9 & 9 \\
\hline & HFOV & 9 & 9 & 9 & 9 & 9 & 9 \\
\hline & PCV & $7.45 \pm 0.06 * * *$ & $7.32 \pm 0.06$ & $7.31 \pm 0.06$ & $7.33 \pm 0.05$ & $7.34 \pm 0.06$ & $7.34 \pm 0.06$ \\
\hline & HFOV & $7.48 \pm 0.09 * * *$ & $7.35 \pm 0.04$ & $7.43 \pm 0.05^{*+}$ & $7.45 \pm 0.06^{* *+}$ & $7.45 \pm 0.05^{* *+}$ & $7.44 \pm 0.05^{*+}$ \\
\hline \multirow{4}{*}{$\begin{array}{l}\mathrm{DO}_{2} \\
\left(\mathrm{ml} / \mathrm{min} / \mathrm{m}^{2}\right) \\
\mathrm{VO}_{2} \\
\left(\mathrm{ml} / \mathrm{min} / \mathrm{m}^{2}\right)\end{array}$} & PCV & $794 \pm 312$ & $781 \pm 216$ & $740 \pm 145$ & $722 \pm 133$ & $677 \pm 114$ & $644 \pm 110$ \\
\hline & HFOV & $662 \pm 157$ & $724 \pm 152$ & $710 \pm 105$ & $677 \pm 99$ & $624 \pm 117$ & $547 \pm 59 *$ \\
\hline & PCV & $184 \pm 42 *$ & $221 \pm 72$ & & & & $194 \pm 44$ \\
\hline & HFOV & $165 \pm 37^{*}$ & $204 \pm 52$ & & & & $188 \pm 24$ \\
\hline $\mathrm{SvO}_{2}$ & PCV & $83 \pm 6 * * *$ & $60 \pm 14$ & & & & $69 \pm 10^{*}$ \\
\hline$[\%]$ & HFOV & $84 \pm 3^{* * *}$ & $62 \pm 8$ & & & & $72 \pm 5^{* *}$ \\
\hline mPaw & PCV & $10 \pm 1 * * *$ & $15 \pm 2$ & $18 \pm 2^{* * * *}$ & $20 \pm 2^{* * *}$ & $23 \pm 2^{* * *}$ & $26 \pm 2^{* * *}$ \\
\hline [cmH2O] & HFOV & $9 \pm 0 * * *$ & $15 \pm 1$ & $18 \pm 1 * * *$ & $21 \pm I^{* * * *}$ & $24 \pm 1 * * *$ & $27 \pm I^{* * * *}$ \\
\hline PIP & PCV & $15 \pm 1 * * * *$ & $25 \pm 3$ & $27 \pm 3 * * *$ & $28 \pm 3^{* * *}$ & $30 \pm 3 * * *$ & $33 \pm 3^{* * *}$ \\
\hline \multirow[t]{2}{*}{ [cmH2O] } & HFOV & $14 \pm 1 * * *$ & $25 \pm 2$ & $20 \pm 1 * * *+$ & $23 \pm 1 * * *+$ & $26 \pm 1 * * *+$ & $29 \pm 1 * * *+$ \\
\hline & Group & $\mathbf{T}_{75}$ & $\mathbf{T}_{90}$ & $\mathbf{T}_{105}$ & $\mathbf{T}_{120}$ & $\mathbf{T}_{135}$ & $\mathbf{T}_{150}$ \\
\hline \multirow{4}{*}{$\begin{array}{l}\text { Number of } \\
\text { animals } \\
\text { pHa }\end{array}$} & $\mathrm{PCV}$ & 9 & 9 & 9 & 9 & 7 & 4 \\
\hline & HFOV & 9 & 8 & 7 & 3 & & \\
\hline & PCV & $7.35 \pm 0.06$ & $7.35 \pm 0.05$ & $7.35 \pm 0.05$ & $7.33 \pm 0.05$ & $7.31 \pm 0,06$ & $7.30 \pm 0,04$ \\
\hline & HFOV & $7.43 \pm 0.04 *+$ & $7.41 \pm 0.05$ & $7.39 \pm 0.04$ & $7.38 \pm 0.04$ & & \\
\hline \multirow{4}{*}{$\begin{array}{l}\mathrm{DO}_{2} \\
(\mathrm{ml} / \mathrm{min}) \\
\mathrm{VO}_{2} \\
(\mathrm{ml} / \mathrm{min})\end{array}$} & PCV & $591 \pm 7 I^{*}$ & $571 \pm 68$ & $551 \pm 65$ & $506 \pm 73$ & $494 \pm 89$ & $475 \pm 74$ \\
\hline & HFOV & $503 \pm 71 * *$ & $461 \pm 72$ & $478 \pm 60$ & $489 \pm 92$ & & \\
\hline & PCV & & & & $183 \pm 27$ & & \\
\hline & HFOV & & & & $194 \pm 18$ & & \\
\hline $\mathrm{SvO2}$ & $\mathrm{PCV}$ & & & & $70 \pm 4$ & & \\
\hline [\%] & HFOV & & & & $66 \pm 9$ & & \\
\hline mPaw & PCV & $28 \pm I^{* * * *}$ & $31 \pm 2$ & $34 \pm 1$ & $36 \pm 2$ & $37 \pm 4$ & $36 \pm 2$ \\
\hline [cmH2O] & HFOV & $29 \pm 2^{* * * *}$ & $32 \pm 3$ & $33 \pm 4$ & $33 \pm 1$ & & \\
\hline PIP & PCV & $35 \pm 2 * * *$ & $38 \pm 2$ & $42 \pm 3$ & $43 \pm 4$ & $45 \pm 6$ & $45 \pm 2$ \\
\hline [cmH2O] & HFOV & $31 \pm 2^{* * * *+}$ & $34 \pm 3$ & $35 \pm 4$ & $35 \pm 1$ & & \\
\hline
\end{tabular}

Data are mean \pm standard deviation; Two-way-ANOVA with repeated measurements (Student-Newman-Keuls post hoc test): $* \mathrm{p}<0.05, * * \mathrm{p}<$ 0.01 , **** $p<0.001$ vs. $\mathrm{T}_{\text {Ali; }}$ HFOV compared with PCV: $+p<0.001$. PCV $=$ pressure controlled ventilation; HFOV = High-frequency oscillatory ventilation; $\mathrm{DO}_{2}=$ oxygen delivery; $\mathrm{VO}_{2}=$ oxygen consumption; $\mathrm{S}_{\mathrm{v}} \mathrm{O}_{2}=$ mixed venous oxygen saturation; $\mathrm{mPaw}=$ mean pulmonary airway pressure; PIP = peak pulmonary airway pressure.

effect of the initial SI might have been reversed in the PCV group because the applied PEEP was possibly not high enough to maintain previously recruited lung areas open. Bond and co-workers failed to show acute volume recruitment after SI, even when PEEP was set above the critical closing pressure of the lung during large tidal volume ventilation [24]. In contrast, Foti et al. showed that volume recruitment manoeuvres can improve oxygenation and alveolar recruitment during conventional ventilation at low PEEP levels [9]. It has been suggested that the collapsed lung, in which low PEEP is being used, benefits more from a RM than lungs already ventilated with high PEEP $[24,25]$. In ARDS patients ventilated with low tidal volumes, derecruitment was reversed by a reexpansion manoeuvre or prevented by an adequate PEEP level [8].

In our study the stepwise rises in mPaw resulted in an improved oxygenation in both groups. At matched mPaw,
HFOV resulted in a significant higher $\mathrm{PaO}_{2} / \mathrm{FiO}_{2}$-Ratio and a lower OI (fig. 2 and 3).

We did not try to achieve normocapnia. Ventilatory settings were fixed in both study groups. This resulted in hypercapnia in the conventional ventilation and in normocapnia in the HFOV group. This is presumably the result of a greater reduction in physiologic deadspace ratio in the HFOV animals, which was again most probably a result of a greater lung volume ensuring a better ventilation/perfusion relationship after the SI. These data are in contrast with recently published randomized controlled trial without RM, since normocapnia was not achievable with HFOV in human and experimental ARDS-trials $[15,26]$.

\section{Hemodynamic effect}

We detected changes in the hemodynamic status during the RM compared to $\mathrm{T}_{\mathrm{Ali}}$. Because of the potential for 


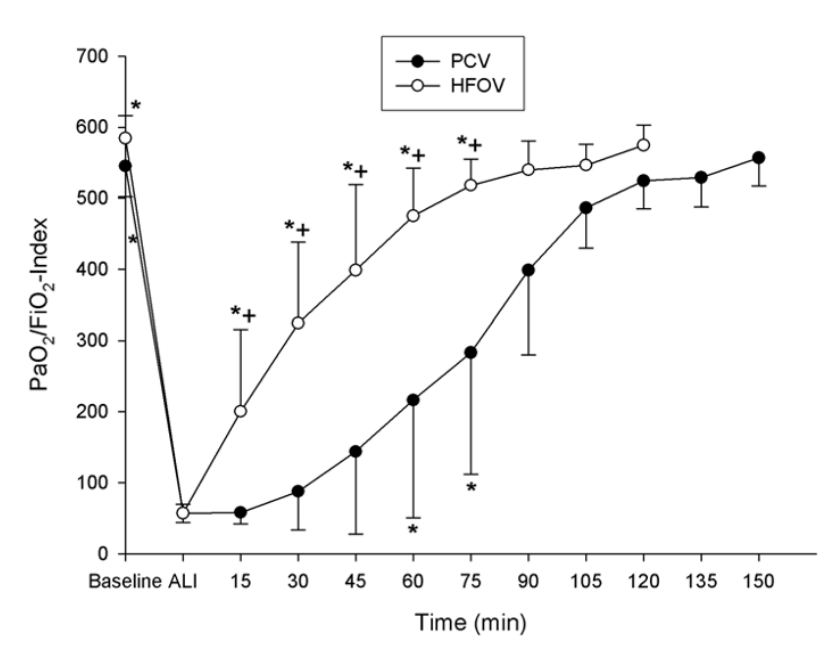

Figure 2

$\mathbf{P a O}_{2} / \mathrm{FiO}_{2}$ - Index. $\mathrm{PaO}_{2} / \mathrm{FiO}_{2}-$ Index (mean $\pm \mathrm{SD}$ ) during recruitment manoeuvre. $\mathrm{PCV}=$ pressure controlled ventilation; HFOV $=$ High-frequency oscillatory ventilation. ${ }^{*} \mathrm{p}<$ 0.00 I vs. $\mathrm{T}_{\text {Ali; }} ; \mathrm{p}<0.00$ I HFOV vs. PCV. $(n=9$ until 75 $\min )$.

hemodynamic compromise, we decided to apply just one SI and an incremental and not decremental mPaw trial. The higher mPaw applied during both respiratory modes was associated with an early and persistent decrease in

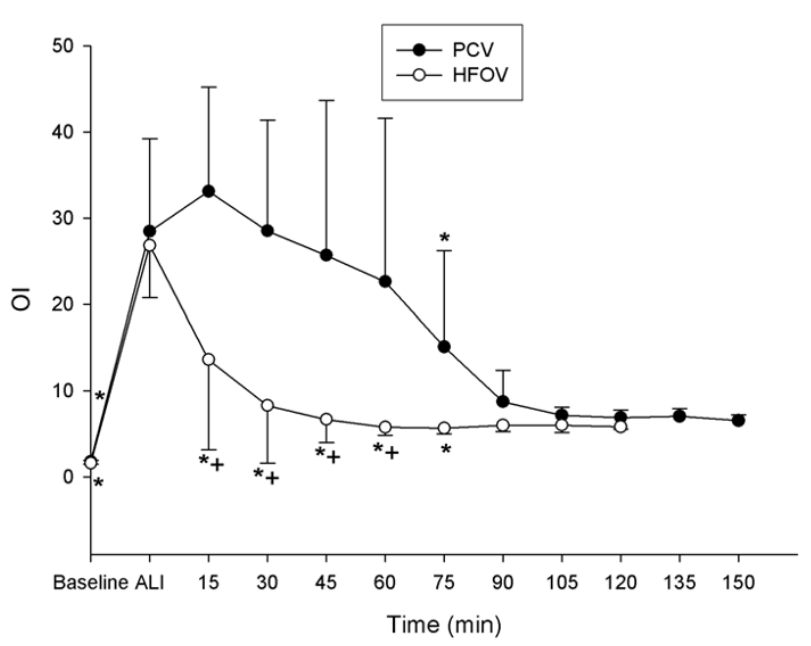

Figure 3

Oxygenation Index (OI). Oxygenation Index (mean \pm SD) during recruitment manoeuvre. $\mathrm{PCV}=$ pressure controlled ventilation; HFOV = High-frequency oscillatory ventilation. $*$ $\mathrm{p}<0.001$ vs. $\mathrm{T}_{\text {Ali }} ;+\mathrm{p}<0.001 \mathrm{HFOV}$ vs. PCV. ( $\mathrm{n}=9$ until 75 $\min )$.

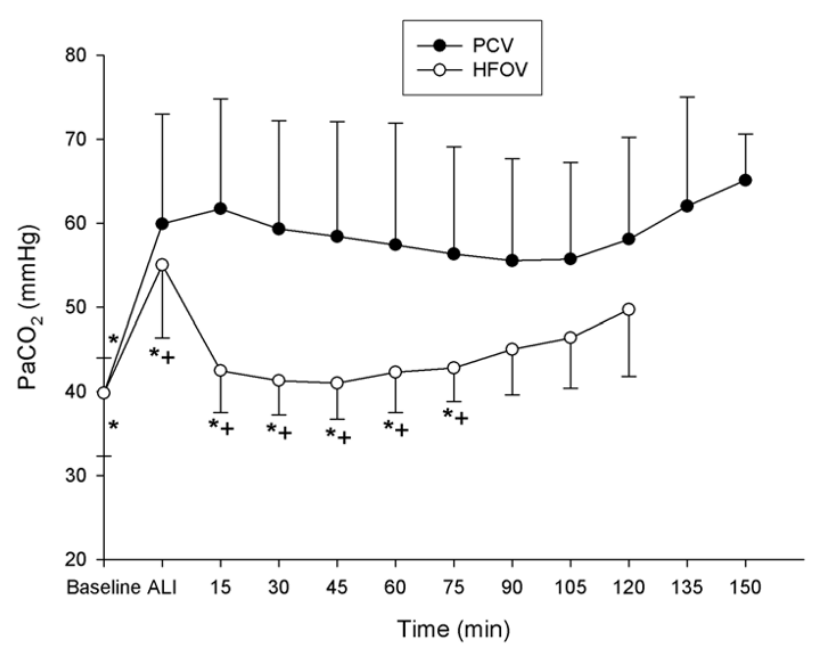

\section{Figure 4}

Partial pressure of arterial carbon dioxide $\left(\mathrm{PaCO}_{2}\right)$. $\mathrm{PaCO}_{2}$ (mean $\pm \mathrm{SD}$ ) during recruitment manoeuvre. $\mathrm{PCV}=$ pressure controlled ventilation; HFOV = High-frequency oscillatory ventilation. $* p<0.0$ I vs. $\mathrm{T}_{\text {Ali }} ;+p<0.0$ I HFOV vs. PCV. ( $n=9$ until $75 \mathrm{~min})$.

CO, a persistent increase in CVP and PCWP and a small decrease in MAP. The reason for these changes was most likely the sustained increase in intrathoracic pressure as described in previous studies [15,27].

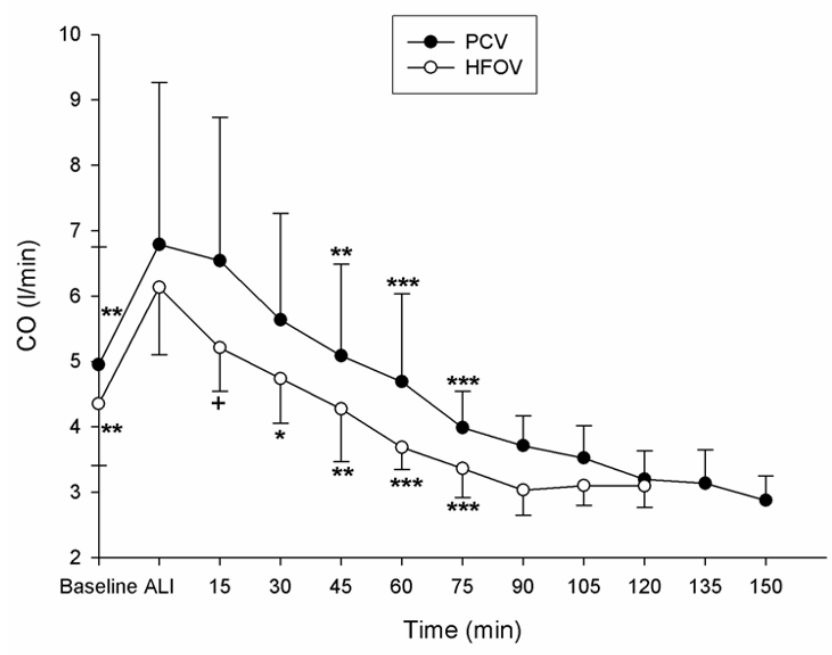

\section{Figure 5}

Cardiac output (CO). CO (mean \pm SD) during recruitment manoeuvre. $\mathrm{PCV}=$ pressure controlled ventilation; $\mathrm{HFOV}=$ High-frequency oscillatory ventilation. $* \mathrm{p}<0.05$, $* *$ $\mathrm{p}<0.0 \mathrm{I}$ and $* * * \mathrm{p}<0.00 \mathrm{I}$ vs. $\mathrm{T}_{\text {Ali }} ; \mathrm{p}<0.0 \mathrm{I}$ HFOV vs. PCV. ( $\mathrm{n}=9$ until $75 \mathrm{~min})$. 


\section{Limitations}

The major limitation of this study is that it was performed in pigs and not in patients. In our study we used a surfactant-depletion lung-lavage model of ARDS. This model does not represent the complexity of the lung injury in ARDS patients. In addition, it is known that surfactant depleted collapsed lungs respond better to PEEP application and RM than lungs with alveolar flooding [25,28].

We used $\mathrm{PaO}_{2}$ as a surrogate marker for lung volume recruitment, since lung volumes and pressure volume relationships have not been directly quantified [29]. It was shown recently, that generation of pressure volume curves is associated with further lung derecruitment [30]. Additional deterioration of oxygenation in our animals after lung injury would have implied a high risk of irreversible hypoxia.

Probably due to the severity of the experimentally induced ARDS, the compliance changes in our model were very consistent across the animals and linear throughout the incremental mPaw-trial. This linearity enabled us to increase mPaw in steps of $3 \mathrm{cmH}_{2} \mathrm{O}$ in the PCV-group by PEEP-augmentation of $3 \mathrm{~cm} \mathrm{H}_{2} \mathrm{O}$. The results are not transferable to other animal models or humans with lungs characterized by different pressurevolume-relationships.

\section{Conclusion}

In this saline lavage induced large porcine model of early severe ARDS, sustained inflations followed by an incremental mean airway pressure trial improved gas exchange and resulted in a significant reduction of pulmonary shunt fraction at a lower mPaw during HFOV than during conventional lung protective ventilation. Large animal long term trials with acquisition of histopathologic and inflammatory cytokine data are needed to evaluate whether the thereby possible reduction of mPaw results in further lung protection. Normocapnia was achieved in HFOV but not in the PCV group, suggesting that large volume swings might not be required to eliminate $\mathrm{CO}_{2}$ in an "open lung" approach.

\section{Competing interests}

The author(s) declare that they have no competing interests.

\section{Authors' contributions}

RMM conceived the study, collected and analysed the data and drafted the manuscript. MK and BZ collected data and performed the statistical analysis. CW and NR participated in the design of the study. JB designed the study protocol and helped writing the manuscript. All authors read and approved the final manuscript.

\section{Acknowledgements}

The authors thank Alois Reichert for technical assistance, Brigitte Paul and Juergen Schoell for logistic and Karin Ulrichs, PhD. for organisatory support. The high frequency oscillatory ventilator was provided by Viasys Healthcare, Hoechberg, Germany.

\section{References}

I. Pinhu L, Whitehead T, Evans T, Griffiths M: Ventilator-associated lung injury. Lancet 2003, 36 I:332-340.

2. Ware $L B$, Matthay MA: The acute respiratory distress syndrome. N Engl J Med 2000, 342: I334- I 349.

3. Tremblay LN, Miatto D, Hamid Q, Govindarajan A, Slutsky AS: Injurious ventilation induces widespread pulmonary epithelial expression of tumor necrosis factor-alpha and interleukin-6 messenger RNA. Crit Care Med 2002, 30:1693-I700.

4. Corbridge TC, Wood LD, Crawford GP, Chudoba MJ, Yanos J, Sznajder Jl: Adverse effects of large tidal volume and low PEEP in canine acid aspiration. Am Rev Respir Dis 1990, I 42:3 I I-315.

5. Amato MB, Barbas CS, Medeiros DM, Magaldi RB, Schettino GP, Lorenzi-Filho G, Kairalla RA, Deheinzelin D, Munoz C, Oliveira R, Takagaki TY, Carvalho CR: Effect of a protective-ventilation strategy on mortality in the acute respiratory distress syndrome. N Engl J Med 1998, 338:347-354.

6. Ventilation with lower tidal volumes as compared with traditional tidal volumes for acute lung injury and the acute respiratory distress syndrome. The Acute Respiratory Distress Syndrome Network. N Engl ] Med 2000, 342: I30 I-I 308.

7. International consensus conferences in intensive care medicine: Ventilator-associated Lung Injury in ARDS. This official conference report was cosponsored by the American Thoracic Society, The European Society of Intensive Care Medicine, and The Societe de Reanimation de Langue Francaise, and was approved by the ATS Board of Directors, July 1999. Am J Respir Crit Care Med 1999, 160:21 18-2124.

8. Richard JC, Maggiore SM, Jonson B, Mancebo J, Lemaire F, Brochard $L$ : Influence of tidal volume on alveolar recruitment. Respective role of PEEP and a recruitment maneuver. Am J Respir Crit Care Med 2001, 163:1609-1613.

9. Foti G, Cereda M, Sparacino ME, De Marchi L, Villa F, Pesenti A: Effects of periodic lung recruitment maneuvers on gas exchange and respiratory mechanics in mechanically ventilated acute respiratory distress syndrome (ARDS) patients. Intensive Care Med 2000, 26:50 I-507.

10. Pelosi P, Cadringher P, Bottino N, Panigada M, Carrieri F, Riva E, Lissoni $A$, Gattinoni L: Sigh in acute respiratory distress syndrome. Am J Respir Crit Care Med 1999, I 59:872-880.

II. Rothen HU, Neumann P, Berglund JE, Valtysson J, Magnusson A, Hedenstierna G: Dynamics of re-expansion of atelectasis during general anaesthesia. Br J Anaesth 1999, 82:55 I-556.

12. Esteban A, Anzueto A, Frutos F, Alia I, Brochard L, Stewart TE, Benito S, Epstein SK, Apezteguia C, Nightingale P, Arroliga AC, Tobin MJ: Characteristics and outcomes in adult patients receiving mechanical ventilation: a 28-day international study. JAMA 2002, 287:345-355.

13. Ferguson ND, Stewart TE: The use of high-frequency oscillatory ventilation in adults with acute lung injury. Respir Care Clin N Am 200I, 7:647-66I.

14. Froese $A B$ : High-frequency oscillatory ventilation for adult respiratory distress syndrome: let's get it right this time! Crit Care Med 1997, 25:906-908.

15. Derdak S, Mehta S, Stewart TE, Smith T, Rogers M, Buchman TG, Carlin B, Lowson S, Granton J: High-frequency oscillatory ventilation for acute respiratory distress syndrome in adults: a randomized, controlled trial. Am J Respir Crit Care Med 2002, 166:80|-808.

16. Arnold JH, Hanson JH, Toro-Figuero LO, Gutierrez J, Berens RJ, Anglin DL: Prospective, randomized comparison of high-frequency oscillatory ventilation and conventional mechanical ventilation in pediatric respiratory failure. Crit Care Med 1994, 22:1530-1539.

17. Gerstmann DR, Minton SD, Stoddard RA, Meredith KS, Monaco F, Bertrand JM, Battisti O, Langhendries JP, Francois A, Clark RH: The Provo multicenter early high-frequency oscillatory ventilation trial: improved pulmonary and clinical outcome in respiratory distress syndrome. Pediatrics 1996, 98:1044-1057. 
18. Kolton M, Cattran CB, Kent G, Volgyesi G, Froese AB, Bryan AC: Oxygenation during high-frequency ventilation compared with conventional mechanical ventilation in two models of lung injury. Anesth Analg 1982, 61:323-332.

19. Hallman M, Merritt TA, Jarvenpaa AL, Boynton B, Mannino F, Gluck $L$, Moore T, Edwards D: Exogenous human surfactant for treatment of severe respiratory distress syndrome: a randomized prospective clinical trial. J Pediatr 1985, 106:963-969.

20. Krishnan RK, Meyers PA, Worwa C, Goertz R, Schauer G, Mammel MC: Standardized lung recruitment during high frequency and conventional ventilation: similar pathophysiologic and inflammatory responses in an animal model of respiratory distress syndrome. Intensive Care Med 2004, 30: I I 95- 1203.

21. Cheney FWJ, Martin WE: Effects of continuous positive-pressure ventilation on gas exchange in acute pulmonary edema. J Appl Physiol I97I, 30:378-38I.

22. Herman S, Reynolds EO: Methods for improving oxygenation in infants mechanically ventilated for severe hyaline membrane disease. Arch Dis Child 1973, 48:612-617.

23. Froese $A B$ : The incremental application of lung-protective high-frequency oscillatory ventilation. Am J Respir Crit Care Med 2002, 166:786-787.

24. Bond DM, McAloon J, Froese AB: Sustained inflations improve respiratory compliance during high-frequency oscillatory ventilation but not during large tidal volume positive-pressure ventilation in rabbits. Crit Care Med I994, 22:1269-1277.

25. Kloot TE, Blanch L, Melynne YA, Weinert C, Adams AB, Marini JJ, Shapiro RS, Nahum A: Recruitment maneuvers in three experimental models of acute lung injury. Effect on lung volume and gas exchange. Am J Respir Crit Care Med 2000, 16 I: I 485- I 494.

26. Brederlau J, Muellenbach R, Kredel M, Greim C, Roewer N: High frequency oscillatory ventilation and prone positioning in a porcine model of lavage-induced acute lung injury. $B M C$ Anesthesiol 2006, 6:4

27. Mehta S, Lapinsky SE, Hallett DC, Merker D, Groll RJ, Cooper AB, MacDonald RJ, Stewart TE: Prospective trial of high-frequency oscillation in adults with acute respiratory distress syndrome. Crit Care Med 200I, 29:1360-1369.

28. Hubmayr RD: Perspective on lung injury and recruitment: a skeptical look at the opening and collapse story. Am J Respir Crit Care Med 2002, 165:1647-1653.

29. McCulloch PR, Forkert PG, Froese AB: Lung volume maintenance prevents lung injury during high frequency oscillatory ventilation in surfactant-deficient rabbits. Am Rev Respir Dis 1988, 137:1185-1192

30. Henzler D, Mahnken A, Dembinski R, Waskowiak B, Rossaint R, Kuhlen R: Repeated generation of the pulmonary pressure-volume curve may lead to derecruitment in experimental lung injury. Intensive Care Med 2005, 31:302-310.

\section{Pre-publication history}

The pre-publication history for this paper can be accessed here:

\section{http://www.biomedcentral.com/1471-2253/6/8/prepub}

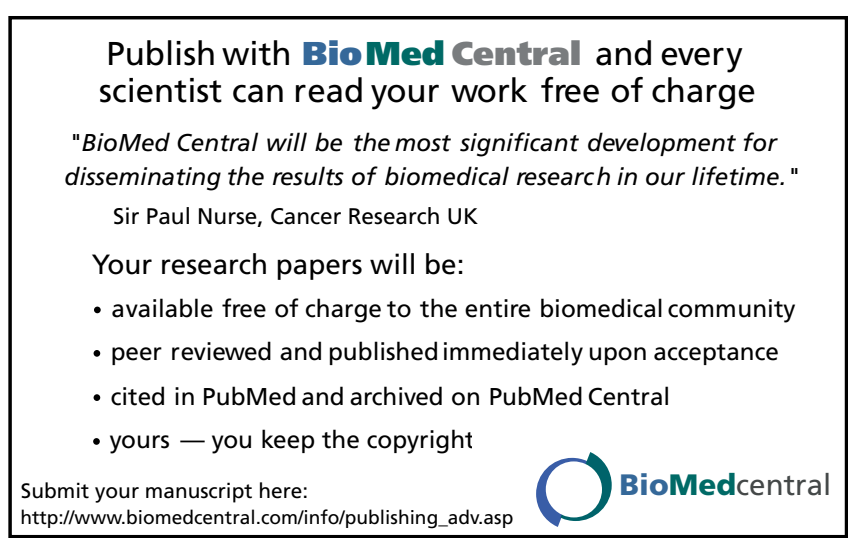

